\title{
Acidemia does not affect outcomes of patients with acute cardiogenic pulmonary edema treated with continuous positive airway pressure
}

\author{
Stefano Aliberti ${ }^{1 *}$, Federico Piffer ${ }^{1}$, Anna Maria Brambilla ${ }^{2}$, Angelo A Bignamini ${ }^{3}$, Valentina D Rosti ${ }^{2}$, \\ Tommaso Maraffi ${ }^{2}$, Valter Monzani', Roberto Cosentini ${ }^{2}$
}

\begin{abstract}
Introduction: A lack of data exists in the literature evaluating acidemia on admission as a favorable or negative prognostic factor in patients with acute cardiogenic pulmonary edema (ACPE) treated with non-invasive continuous positive airway pressure (CPAP). The objective of the present study was to investigate the impact of acidemia on admission on outcomes of ACPE patients treated with CPAP.
\end{abstract}

Methods: This was a retrospective, observational study of consecutive patients admitted with a diagnosis of ACPE to the Emergency Department of IRCCS Fondazione Cà Granda Ospedale Maggiore Policlinico, Milan, Italy, between January 2003 and December 2006, treated with CPAP on admission. Two groups of patients were identified: subjects with acidemia (acidotic group), and those with a normal pH on admission (controls). The primary endpoint was clinical failure, defined as switch to bi-level ventilation, switch to endotracheal intubation or inhospital mortality.

Results: Among the 378 patients enrolled, 290 (77\%) were acidotic on admission. A total of 28 patients (9.7\%) in the acidotic group and eight patients (9.1\%) among controls experienced a clinical failure (odds ratio $=1.069,95 \%$ confidence interval $=0.469$ to $2.438, P=0.875$ ). Survival analysis indicates that, among acidotic patients, the time at which $50 \%$ of patients reached the 7.35 threshold was 173 minutes (95\% confidence interval $=153$ to 193). Neither acidemia $(P=0.205$ ) nor the type of acidosis on admission (respiratory acidosis, $P=0.126$; metabolic acidosis, $P=0.292$; mixed acidosis, $P=0.397$ ) affected clinical failure after adjustment for clinical and laboratory factors in a multivariable logistic regression model.

Conclusions: Neither acidemia nor the type of acidosis on admission should be considered risk factors for adverse outcomes in ACPE patients treated with CPAP.

\section{Introduction}

International guidelines suggest the use of non-invasive continuous positive airways pressure (CPAP) as first-line intervention in patients with acute cardiogenic pulmonary edema (ACPE) [1]. CPAP has proven to be easier to use, quicker to implement in clinical practice and to carry smaller associated costs in comparison with noninvasive ventilation (NIV) [2]. In light of these findings, CPAP has also been also used to treat ACPE patients

\footnotetext{
* Correspondence: stefano.aliberti@policlinico.mi.it

'Dipartimento toraco-polmonare e cardio-circolatorio, University of Milan, IRCCS Fondazione Cà Granda Ospedale Maggiore Policlinico, via F. Sforza 35, 20122 Milan, Italy

Full list of author information is available at the end of the article
}

outside the intensive care unit or the Emergency Department, as in the general ward or during prehospital care [3].

The rate of mortality in ACPE patients treated with CPAP is reported to be up to $13 \%[4,5]$. Therefore, it is crucial for healthcare providers to identify risk factors for failure of CPAP treatment, in order to better allocate medical resources and improve clinical outcomes of ACPE patients.

Severity of acidemia on admission, as well as lack of improvement of respiratory acidosis during the first few hours of NIV, have emerged as important predictors of failure in patients suffering of hypercapnic respiratory 
failure [6-8]. Acidemia on admission has been also shown to predict NIV failure a few days after its initial application in patients who have previously experienced an initial improvement of clinical status and blood gas values [9]. In clinical practice, acidotic patients with ACPE are commonly considered more severe in comparison with nonacidotic patients. In view of this consideration, the largest clinical trial that has evaluated CPAP and NIV in ACPE patients enrolled acidotic patients [10].

On the contrary, acidemia has not been identified as a predictor of NIV failure in patients with hypoxemic respiratory failure $[5,11]$. Conflicting data exist in the literature alternatively considering respiratory acidosis a favorable or a negative prognostic factor in ACPE patients. Particularly, ACPE patients who suffered respiratory acidosis on admission were identified as those exhibiting a better response to CPAP treatment [12].

To define the impact of acidemia on clinical outcomes of ACPE patients treated with CPAP, the present study has the following objectives: to compare outcomes and physiological measurements of patients with acidemia versus those with normal $\mathrm{pH}$ values on admission; and to evaluate outcomes and physiological measurements of patients with different types of acidosis on admission.

\section{Materials and methods}

\section{Setting and subjects}

This was a retrospective, observational study of consecutive patients admitted with a diagnosis of ACPE to the Emergency Department of IRCCS Fondazione Ca' Granda Ospedale Maggiore Policlinico, Milan, Italy between January 2003 and December 2006.

Adult patients who satisfied the criteria for ACPE and who were treated with CPAP on admission were enrolled in the study. Patients with alkalemia on admission were excluded.

The diagnosis of ACPE was established on the basis of medical history (acute severe dyspnea) and typical physical findings (widespread pulmonary rales), with chest radiography confirming pulmonary vascular congestion. Criteria for application of CPAP included at least one of the following: severe acute respiratory failure $\left(\mathrm{PaO}_{2} /\right.$ $\mathrm{FiO}_{2}$ ratio $<300$ ); respiratory rate exceeding 30 breaths/ minute or use of accessory respiratory muscles or paradoxical abdominal motion; and respiratory acidosis $(\mathrm{pH}$ $<7.350, \mathrm{PaCO}_{2} \geq 45 \mathrm{mmHg}$ ).

All patients enrolled in the study underwent high-flow CPAP (90 to 140 l/minute; VitalSigns Inc., Totowa, NJ, USA) as the first choice of treatment, in addition to oxygen and standard medical treatment. Interfaces used were a facemask (VitalSigns Inc.) or a helmet (StarMed, Mirandola, Italy) with a positive end-expiratory pressure
(PEEP) valve (VitalSigns Inc.). CPAP was not applied in ACPE patients if any among the following findings was present: immediate need for endotracheal intubation; impairment of consciousness (Kelly scale >4) [13]; and hemodynamic instability (systolic blood pressure $<90$ $\mathrm{mmHg}$ ). Criteria for discontinuation from CPAP included all of the following: absence of respiratory distress; respiratory rate $<25$ beats/minute; hemodynamic stability; pH $>7.35$; and $\mathrm{PaO}_{2} / \mathrm{FiO}_{2}$ ratio $>300$ or oxygen saturation $\geq 95 \%$.

Criteria to switch from CPAP to bi-level ventilation were a lack of improvement or a worsening of ventilation and/or gas exchange at a blood gas examination performed 30 minutes/1 hour after initiation of CPAP treatment, in the absence of criteria for endotracheal intubation (ETI). Criteria for ETI were at least one among the following: impairment of consciousness; hemodynamic instability (systolic blood pressure $<90 \mathrm{mmHg}$ ); cardiac and/or respiratory arrest; and a lack of improvement or a worsening of ventilation and/ or gas exchange at a blood gas examination performed 1 hour after initiation of bi-level treatment.

The above criteria for the application of CPAP in ACPE patients as well as the protocol of medical treatment were applied according to local standard operating procedures. Each patient received medical treatment according to the local standard of care: intravenous furosemide 40 to $100 \mathrm{mg}$ based on fluid retention (or at least doubling the dose at home) targeted on the urinary output; intravenous isosorbide dinitrate on continuous infusion starting at $1 \mathrm{mg} /$ hour up to $10 \mathrm{mg}$ /hour; intravenous morphine up to $4 \mathrm{mg}$ and vasopressors in case of hypotension. No subjects receiving invasive or noninvasive pressure support ventilation before CPAP treatment were included in the study.

\section{Study design}

Records of all the enrolled patients were carefully reviewed. Data on admission, before and during CPAP treatment, and during hospitalization were collected, and included the following: demographic information and past medical history; clinical characteristics; laboratory evaluation performed on arterial sample; and information needed to derive the Simplified Acute Physiology Score II [14]. Arterial blood gas evaluation on admission was considered for those samples obtained within 15 minutes from admission to the hospital, based on local standard operating procedures. A group of investigators of the Emergency Department, Fondazione Ca' Granda, Milan, Italy validated the quality of data by checking for discrepancies and inconsistencies before cases were entered into a database. The Institutional Review Board of the IRCCS Fondazione Ca' Granda Ospedale Maggiore 
Policlinico, Milan approved the study. The study was in compliance with the Helsinki Declaration; informed consent was waived by the Institutional Review Board.

\section{Study definitions}

The normal $\mathrm{pH}$ range was considered 7.35 to 7.45 . Alkalemia was considered if the $\mathrm{pH}$ value on admission was more than 7.45. Acidemia was considered if the $\mathrm{pH}$ value on admission was less than 7.35. Respiratory acidosis was considered when acidemia was identified with $\mathrm{PaCO}_{2} \geq 45 \mathrm{mmHg}$ and bicarbonates $\left(\mathrm{HCO}_{3}{ }^{-}\right) \geq 22$ $\mathrm{mmol} / \mathrm{l}$. Metabolic acidosis was considered when acidemia was identified with $\mathrm{PaCO}_{2}<45 \mathrm{mmHg}$ and $\mathrm{HCO}_{3}{ }^{-}<22 \mathrm{mmol} / \mathrm{l}$. Mixed acidosis was considered when acidemia was identified with $\mathrm{PaCO}_{2} \geq 45 \mathrm{mmHg}$ and $\mathrm{HCO}_{3}{ }^{-}<22 \mathrm{mmol} / \mathrm{l}$.

\section{Study groups}

Patients with ACPE treated with CPAP were divided into two groups according to the $\mathrm{pH}$ value on admission: subjects with acidemia (acidotic group), and those with a normal $\mathrm{pH}$ (controls). Among patients of the acidotic group, three subgroups were identified according to $\mathrm{PaCO}_{2}$ and $\mathrm{HCO}_{3}{ }^{-}$values: patients with respiratory acidosis, patients with metabolic acidosis, and patients with mixed acidosis.

\section{Endpoints}

The primary endpoint was clinical failure, defined as at least one among: a switch to non-invasive bi-level ventilation, a switch to ETI, and inhospital mortality.

A switch to bi-level ventilation was applied when both blood gas values were unchanged/worsened with CPAP and criteria for ETI were not fulfilled. ETI was performed according to our local standard operating procedures. Inhospital mortality was defined as death by any cause occurring during hospitalization. ACPE-related mortality was defined as death occurring during the episode of ACPE. Late mortality was defined as death occurring after the resolution of the episode of ACPE. Our local standard operating procedures define an episode of ACPE as being resolved when all the criteria for discontinuation of CPAP mentioned above are reached.

The secondary endpoint was the length of stay in the hospital. This length of stay was calculated as the number of days from the date of admission to the date of discharge, and was censored at 14 days in an effort to capture only the ACPE-related length of stay in the hospital.

\section{Statistical analysis}

All data were statistically analyzed with SPSS for Windows (version 14.0; SPSS Inc., Chicago, IL, USA). Descriptive statistics are reported as the mean with standard deviation or counts and proportions as appropriate. Patient characteristics were compared between groups. Summary statistics for all continuous explanatory variables are presented as means with differences between groups compared by independent $t$ test. Categorical explanatory variables are summarized as percentages with differences between groups analyzed using the chi-square test or the Fisher exact test where appropriate. The time to event was analyzed by Kaplan-Meier survival analysis. The association between clinical failure and acidemia on admission was analyzed using multiple logistic regression. All explanatory variables considered of clinical relevance and those previously found to be significantly associated with mortality in ACPE patients treated with CPAP were incorporated into the model [5]. The time course of continuous variables was analyzed by repeated-measures analysis of variance after replacing the missing values with the last observation carried forward technique. $P<0.05$ was considered statistically significant.

\section{Results}

\section{Acidotic population}

Among the 419 ACPE patients treated with CPAP who were enrolled during the study period, the $\mathrm{pH}$ value within 15 minutes from admission was not available in 23 patients, while 18 patients were excluded because of alkalemia on admission. The final study population accounted for 378 patients: 290 (77\%) were acidotic on admission (acidotic group), while 88 were controls. Baseline characteristics and the CPAP setting of the acidotic group and controls are summarized in Table 1.

The mean \pm standard deviation duration of CPAP treatment was $318 \pm 485$ minutes and $262 \pm 198 \mathrm{~min}$ utes in the acidotic group and controls, respectively $(P=$ $0.289)$. The mean \pm standard deviation $\mathrm{FiO}_{2}$ during CPAP was $48 \pm 11 \%$ and $47 \pm 9 \%$ in the acidotic group and in controls, respectively $(P=0.219)$. The mean \pm standard deviation PEEP during CPAP was $8.1 \pm 1.7$ $\mathrm{cmH}_{2} \mathrm{O}$ and $7.9 \pm 1.4 \mathrm{cmH}_{2} \mathrm{O}$ in the acidotic group and in controls, respectively $(P=0.229)$.

A total of 28 patients $(9.7 \%)$ in the acidotic group and eight patients (9.1\%) among controls experienced a clinical failure (odds ratio $=1.069 ; 95 \%$ confidence interval $=$ 0.469 to $2.438 ; P=0.875$ ) (see Table 2). Acidemia on admission did not affect clinical failure after adjustment for age, history of acute myocardial infarction, hypocapnia, normotension and $\mathrm{PaO}_{2} / \mathrm{FiO}_{2}$ ratio in a multivariable logistic regression model $(P=0.205)$.

The crude proportion of clinical failure in the study population is presented in Figure 1, split by $\mathrm{pH}$ value on admission. The $95 \%$ confidence interval of the controls group included the point estimate and most of the confidence intervals of the other groups. Figure 2 shows the 
Table 1 Baseline characteristics on admission and before continuous positive airway pressure treatment

\begin{tabular}{|c|c|c|c|}
\hline Variable & Acidotic group $(n=290)$ & Controls $(n=88)$ & $P$ value \\
\hline \multicolumn{4}{|l|}{ Demographics } \\
\hline Male & $143(49)$ & $36(41)$ & $0.167^{\mathrm{a}}$ \\
\hline Age (years) & $80 \pm 10(n=290)$ & $81 \pm 9.5(n=88)$ & $0.360^{b}$ \\
\hline \multicolumn{4}{|l|}{ Comorbidities } \\
\hline Chronic obstructive pulmonary disease & $84(29)$ & $17 / 86(20)$ & $0.091^{\mathrm{a}}$ \\
\hline Essential hypertension & $162(56)$ & $46 / 86(54)$ & $0.697^{\mathrm{a}}$ \\
\hline Diabetes mellitus & $72(25)$ & 19/86 (22) & $0.603^{\mathrm{a}}$ \\
\hline Congestive heart failure & $165(57)$ & $51 / 86(59)$ & $0.692^{\mathrm{a}}$ \\
\hline Chronic renal failure & $76(26)$ & $13 / 86(15)$ & $0.034^{\mathrm{a}}$ \\
\hline \multicolumn{4}{|l|}{ Severity of the disease } \\
\hline Simplified Physiologic Acute Score ॥ & $42 \pm 6.7(n=258)$ & $40 \pm 8.1(n=74)$ & $0.014^{b}$ \\
\hline \multicolumn{4}{|l|}{ Physical findings } \\
\hline Systolic blood pressure $(\mathrm{mmHg})$ & $173 \pm 30(n=286)$ & $170 \pm 31(n=87)$ & $0.328^{b}$ \\
\hline Diastolic blood pressure (mmHg) & $99 \pm 20(n=283)$ & $97 \pm 19(n=87)$ & $0.391^{b}$ \\
\hline Systolic $<140 \mathrm{mmHg}$ and diastolic $<90 \mathrm{mmHg}$ & $32(11)$ & $9(10)$ & $0.802^{b}$ \\
\hline Heart rate (beats/minute) & $116 \pm 22(n=283)$ & $121 \pm 22(n=87)$ & $0.163^{b}$ \\
\hline Heart rate $>100$ beats $/$ minute & 197/283 (70) & $53 / 87(61)$ & $0.130^{a}$ \\
\hline Respiratory rate (breaths/minute) & $41 \pm 6.1(n=175)$ & $39 \pm 6.9(n=64)$ & $0.016^{\mathrm{b}}$ \\
\hline Respiratory rate $\geq 40$ breaths/minute & $120 / 175(69)$ & $30 / 64(47)$ & $0.002^{\mathrm{a}}$ \\
\hline \multicolumn{4}{|l|}{ Arterial blood gas analysis } \\
\hline $\mathrm{pH}$ & $7.22 \pm 0.09(n=290)$ & $7.39 \pm 0.03(n=88)$ & Not applicable \\
\hline $\mathrm{PaCO}_{2}(\mathrm{mmHg})$ & $53 \pm 16(n=290)$ & $36 \pm 6.6(n=88)$ & $<0.001^{\mathrm{b}}$ \\
\hline Bicarbonates (mmol/l) & $22 \pm 5.3(n=288)$ & $22 \pm 3.8(n=88)$ & $0.330^{\mathrm{b}}$ \\
\hline $\mathrm{PaO}_{2} / \mathrm{FiO}_{2}$ ratio & $178 \pm 93(n=283)$ & $222 \pm 82(n=87)$ & $<0.001^{\mathrm{b}}$ \\
\hline $\mathrm{PaO}_{2} / \mathrm{FiO}_{2}$ ratio $<200$ & 184/283 (65) & $32 / 87(37)$ & $<0.001^{\mathrm{a}}$ \\
\hline Acute myocardial infarction on admission & $43(15)$ & $14(16)$ & $0.804^{\mathrm{a}}$ \\
\hline \multicolumn{4}{|l|}{ CPAP setting } \\
\hline Initial $\mathrm{FiO}_{2}(\%)$ & $49.7 \pm 12.1(n=288)$ & $48.6 \pm 11.4(n=88)$ & $0.421^{b}$ \\
\hline Initial PEEP $\left(\mathrm{cmH}_{2} \mathrm{O}\right)$ & $9.7 \pm 2.0(n=290)$ & $9.7 \pm 1.3(n=88)$ & $0.927^{b}$ \\
\hline \multicolumn{4}{|l|}{ Device } \\
\hline Face mask & $38(19)$ & $15(24)$ & $0.475^{\mathrm{a}}$ \\
\hline Helmet & $157(81)$ & $48(76)$ & \\
\hline Information not available & 95 & 29 & \\
\hline
\end{tabular}

Demographics, comorbidities, severity of the disease, clinical and laboratory findings on admission and before continuous positive airway pressure (CPAP) treatment of the study population, according to the presence or absence of acidemia on admission. Data presented as number (\%) or mean \pm standard deviation. $\mathrm{PaCO}_{2}$, partial pressure of carbon dioxide in arterial blood; $\mathrm{PaO}_{2} / \mathrm{FiO}_{2}$, partial pressure of oxygen in arterial blood/inspired oxygen fraction; $\mathrm{PEEP}$, positive end-expiratory pressure. ${ }^{\mathrm{a} C h i-s q u a r e ~ t e s t . ~}{ }^{\mathrm{b}}$ Unpaired $t$ test.

Table 2 Clinical endpoints of the study population, according to presence or absence of acidemia on admission

\begin{tabular}{|c|c|c|c|}
\hline Variable & Acidotic group ( $n=290,77 \%)$ & Controls $(n=88,23 \%)$ & $P$ value (chi-square test) \\
\hline Clinical failure & $28(9.7)$ & $8(9.1)$ & 0.875 \\
\hline Change to bi-level & $5(1.7)$ & $0(0)$ & 0.215 \\
\hline Change to intubation & $6(2.1)$ & $0(0)$ & 0.174 \\
\hline ACPE-related mortality ${ }^{a}$ & $6(2.1)$ & $1(1.1)$ & 0.484 \\
\hline Late mortality ${ }^{\mathrm{b}}$ & $17(6.0)$ & $7(8.1)$ & 0.488 \\
\hline In-hospital mortality ${ }^{b}$ & $23(8.2)$ & $8(9.3)$ & 0.738 \\
\hline Length of hospital stay (days) & $11 \pm 6.9$ & $11 \pm 6.3$ & 0.617 \\
\hline
\end{tabular}

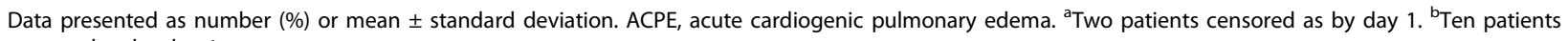
censored as by day 1 . 


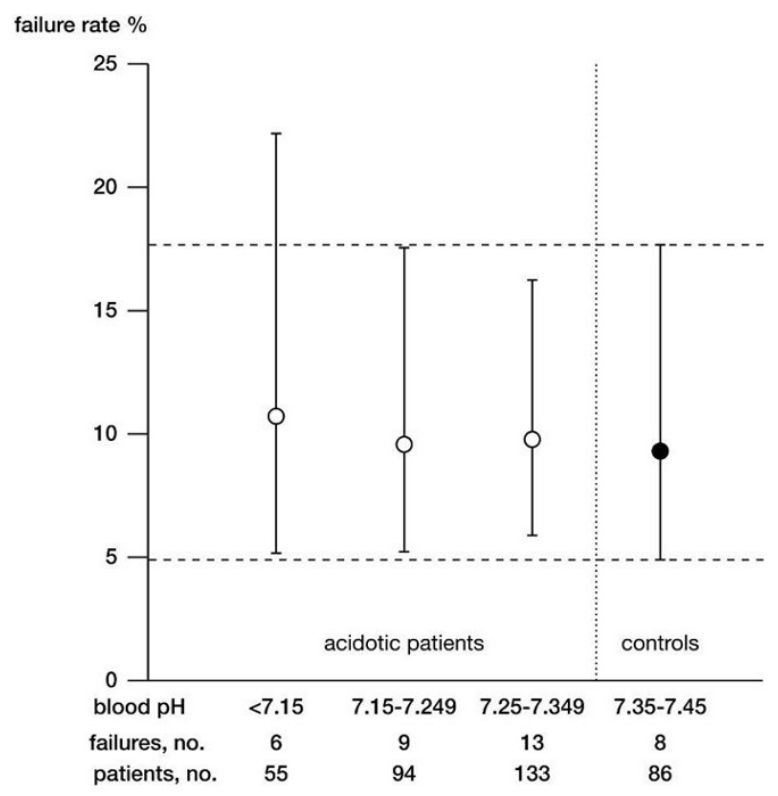

Figure 1 Clinical failure rate of the study population by $\mathrm{pH}$ value on admission. The $95 \%$ confidence intervals of the control group are depicted with dashed horizontal lines.

time course of the mean arterial $\mathrm{pH}$ in the study population. Survival analysis indicates that, among acidotic patients, the time at which $50 \%$ of patients reached the 7.35 threshold was 173 minutes (95\% confidence interval $=153$ to 193$)$ (see Figure 3 ).

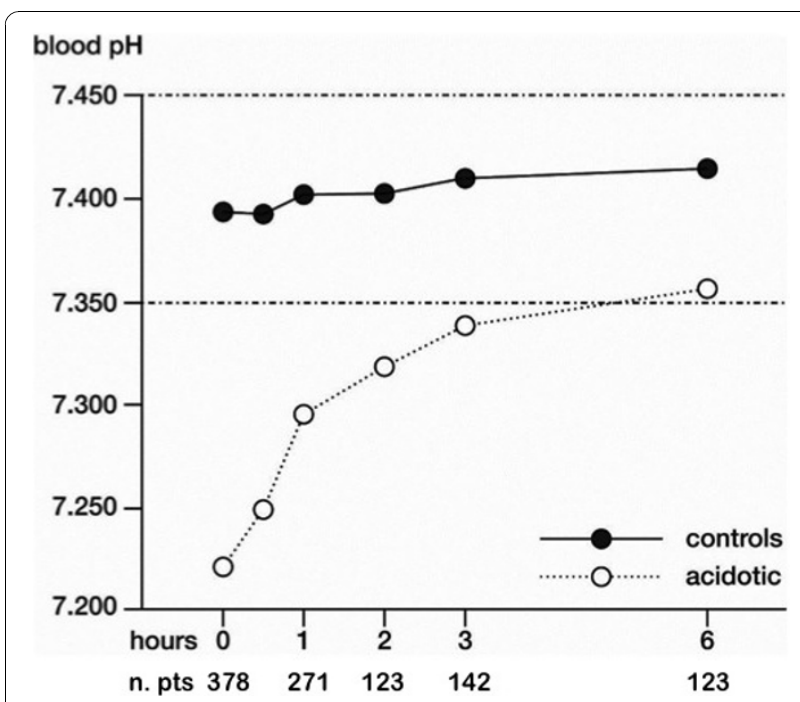

Figure 2 Time course of $\mathrm{pH}$ during continuous positive airways pressure treatment. The time course of mean arterial blood $\mathrm{pH}$ during continuous positive airways pressure treatment in the acidotic group and in controls. Adjusted for age and sex; missing data replaced with the last observation carried forward technique.

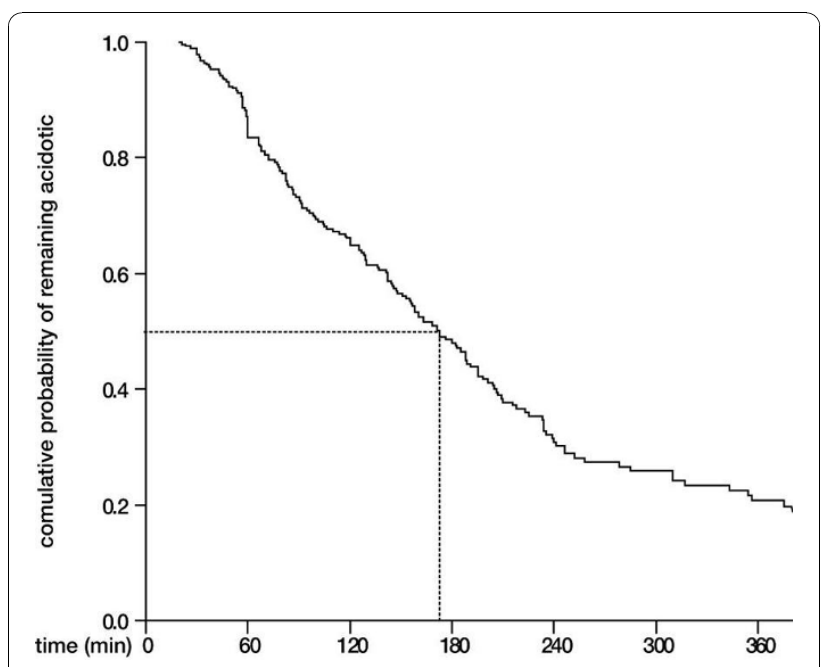

Figure 3 Survival analysis of time to $\mathrm{pH} \geq 7.350$ among acidotic patients. Dotted lines indicate the time at which $50 \%$ of the sample reached the threshold $\mathrm{pH}$ (173 minutes).

\section{Respiratory, metabolic and mixed acidotic populations}

Among the 290 acidotic patients, 13 could not be further classified. Among the other 277 patients, 122 (44\%) showed a respiratory acidosis, 89 (32\%) a metabolic acidosis, and 66 (24\%) a mixed acidosis on admission. The baseline characteristics and CPAP setting of the acidotic population are summarized in the supplemental digital content in Additional file 1, according to the type of acidemia on admission.

A total of 12 patients (10\%) with respiratory acidosis, 11 patients (13\%) with metabolic acidosis, four patients (6.2\%) with mixed acidosis and eight controls (9.3\%) experienced clinical failure $(P=0.613)$ (see Table 3$)$. The type of acidosis on admission did not affect clinical failure after adjustment for age, history of acute myocardial infarction, hypocapnia, normotension and $\mathrm{PaO}_{2} /$ $\mathrm{FiO}_{2}$ ratio in a multivariable logistic regression model (respiratory acidosis, $P=0.126$; metabolic acidosis, $P=$ 0.292; mixed acidosis $P=0.397$ ).

The time course of both $\mathrm{pH}$ and $\mathrm{PaCO}_{2}$ values during CPAP treatment in the acidotic groups, based on diagnosis at admission, as well as in controls is depicted in Figure 4, after replacing the missing values according to the last observation carried forward technique and after adjustment for age, sex and systolic blood pressure. An increase in $\mathrm{pH}$ values was detected in all groups of patients regardless of the type of acidosis, while a decrease in $\mathrm{PaCO}_{2}$ values was observed in mixed and respiratory acidosis patients.

\section{Discussion}

The present study indicates that acidemia on admission is not a risk factor for adverse outcomes in ACPE patients treated with CPAP. Furthermore, not even the 
Table 3 Clinical endpoints of the study population based on type of acidosis on admission

\begin{tabular}{|c|c|c|c|c|c|}
\hline Variable & $\begin{array}{l}\text { Respiratory acidosis } \\
(n=122)\end{array}$ & $\begin{array}{l}\text { Metabolic acidosis } \\
(n=89)\end{array}$ & $\begin{array}{l}\text { Mixed acidosis } \\
(n=66)\end{array}$ & $\begin{array}{l}\text { Controls } \\
(n=88)\end{array}$ & $\begin{array}{l}P \text { value } \\
\text { (chi-square test) }\end{array}$ \\
\hline Clinical failure & $12(10)$ & $11(13)$ & $4(6.2)$ & $8(9.3)$ & 0.613 \\
\hline Change to bi-level & $5(4.1)$ & $0(0)$ & $0(0)$ & $0(0)$ & 0.018 \\
\hline Change to intubation & $1(0.8)$ & $2(2.2)$ & $2(3.0)$ & $0(0)$ & 0.341 \\
\hline ACPE-related mortality & $1(0.8)$ & $4(4.5)$ & $1(1.5)$ & $1(1.1)$ & 0.237 \\
\hline Late mortality & $8(6.8)$ & $7(8)$ & $2(3.1)$ & $7(8.1)$ & 0.595 \\
\hline In-hospital mortality & $9(7.6)(\mathrm{Cl}, 4.1$ to 14.1$)$ & $11(12.6)(\mathrm{Cl}, 7.4$ to 21.7$)$ & $3(4.6)(\mathrm{Cl}, 1.6$ to 13.1$)$ & $8(9.3)(\mathrm{Cl}, 4.9$ to 17.7$)$ & 0.351 \\
\hline Length of hospital stay (days) & $11 \pm 7$ & $11 \pm 9$ & $10 \pm 5$ & $13 \pm 22$ & $0.582^{\mathrm{a}}$ \\
\hline
\end{tabular}

Data presented as number (\%) or mean \pm standard deviation. ACPE: acute cardiogenic pulmonary edema; $\mathrm{Cl}, 95 \%$ confidence interval. ${ }^{\mathrm{a}}$ One-way analysis of variance.

type of acidosis on admission - respiratory, metabolic or mixed - impacts clinical outcomes of ACPE patients treated with CPAP.

Among our cohort of ACPE patients treated with CPAP, more than three-quarters were acidotic on admission. Our acidotic patients showed similar clinical and laboratory characteristics on admission in comparison with the 346 ACPE acidotic patients treated with CPAP enrolled in the randomized controlled trial by Gray and coworkers [10]. The present study, however, reported lower ACPE-related, late and inhospital mortality rates than those reported in that trial. Possible explanations could be found in the CPAP setting (ventilator with a low initial PEEP), as well as the length of treatment used in the study by Gray and colleagues. In this last study the mean duration of CPAP treatment was 2 to 3 hours. We showed that, while CPAP treatment in acidotic ACPE patients did actually bring $50 \%$ of patients to a $\mathrm{pH}$ value above 7.35 within 3 (2.5 to 6) hours, the treatment nevertheless had to be protracted for at least 6 hours before the mean $\mathrm{pH}$ crossed the threshold of 7.35.
We found that acidemia on admission is not a risk factor for failure in ACPE patients treated with CPAP. To date, no studies have evaluated the impact of the degree of acidemia on admission on outcomes of ACPE patients treated with CPAP. We found that the degree of acidemia on admission seems not to be associated with failure. This surprising finding could be explained by the rapidity of the resolution of acidemia in our ACPE patients during CPAP treatment. The increase of $\mathrm{pH}$ seems to be particularly crucial during the first hours of CPAP treatment, and thus the $\mathrm{pH}$ evaluation during this timeframe would be a better marker of prognosis rather than the single value of $\mathrm{pH}$ on admission.

One of the main implications of these findings is that acidotic patients with ACPE undergoing CPAP treatment should not be considered more severe than those with a normal $\mathrm{pH}$ value on admission. On the other hand, other clinical and laboratory factors should be considered in the severity assessment of the ACPE population treated with CPAP, such as advanced age, normal-to-low blood pressure, hypocapnia, or severe alteration of gas exchange [5].

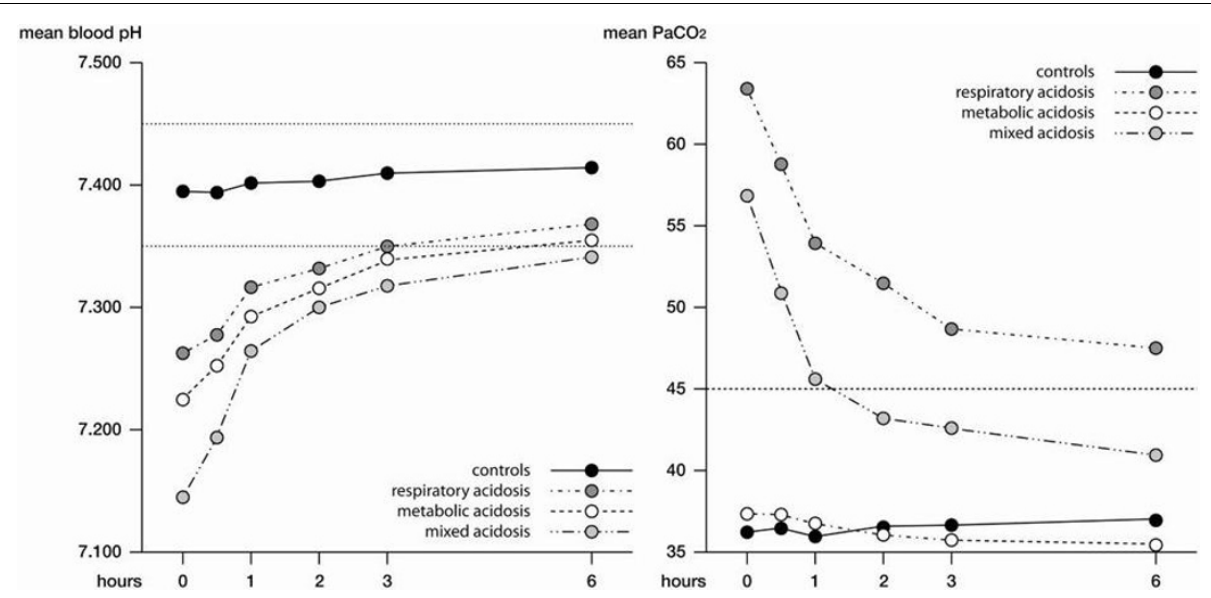

Figure 4 Time course of $\mathrm{pH}$ and $\mathrm{PaCO}_{2}$ during continuous positive airways pressure treatment. Time course of pH and partial pressure of carbon dioxide in arterial blood $\left(\mathrm{PaCO}_{2}\right)$ during continuous positive airways pressure treatment in the controls and in the acidotic group according to the diagnosis (after replacing the missing values according to the last observation carried forward technique and after adjustment for age, sex and systolic blood pressure). 
We found that the type of acidosis on admission (respiratory, metabolic as well as mixed acidosis) does not significantly modify the clinical outcomes in ACPE patients treated with CPAP. ACPE patients with respiratory acidosis on admission undergoing CPAP treatment seem to benefit from this technique. In our study, we found a decrease in $\mathrm{PaCO}_{2}$ levels with a consequent recovery of $\mathrm{pH}$ values during $\mathrm{CPAP}$ treatment in respiratory acidotic patients. An explanation for this finding could be identified in the rationale of the increase of $\mathrm{PaCO}_{2}$ during an episode of ACPE. The etiology of hypoventilation as a sign of pump failure is twofold. On the one hand, such as among patients with acute exacerbation of chronic bronchitis, hypercapnia, often acute on chronic, occurs due to an increased load of the respiratory system and reduced muscular force related to the presence of bronchial obstruction and intrinsic PEEP. On the other hand, such as among patients with ACPE without chronic pump failure, the acute hypoventilation is strictly related to decreased compliance due to parenchymal causes (interstitial/ alveolar flooding), and is thus easily reversed by the alveolar recruitment induced by PEEP. Our findings support data from Bellone and colleagues, who in an elegant randomized controlled trial showed that CPAP could be used in acidotic patients [11]. Based on these data, excluding a priori the use of CPAP in ACPE patients who present respiratory acidosis on admission could not be justified.

We also found an improvement in $\mathrm{pH}$ values in ACPE patients with metabolic acidosis on admission undergoing CPAP treatment. This interesting finding could be explained in light of beneficial effects of the application of PEEP on the heart and hemodynamics, as well as tissue perfusion in patients with ACPE. The most severe ACPE patients treated with CPAP in our population were those with mixed acidosis on admission who showed the lowest $\mathrm{pH}$ values, mainly because of a double effect on both the respiratory and metabolic systems. During CPAP treatment, we found these patients to have a quicker increase of $\mathrm{pH}$ values in comparison with the other acidotic patients, in light of the double action of CPAP on both respiratory mechanics and hemodynamics.

In view of its retrospective design, a weakness of our study could be a deficiency in accurately collecting some history and clinical information. To our knowledge, the present study is the first to evaluate the impact of different acidosis patterns on admission in ACPE patients treated with CPAP. This study is strengthened by a large sample size of consecutive ACPE patients. Moreover, our findings are representative of an unselected population, and our conclusions can thus be easily generalized.

\section{Conclusions}

Neither acidemia nor the type of acidosis on admission should be considered a risk factor for adverse outcomes in ACPE patients treated with CPAP. Furthermore, we suggest that nonacidotic patients should be included in future clinical trials, being at least as severe as the acidotic population.

\section{Key messages}

- Acidemia on admission is not a risk factor for adverse outcomes in patients with ACPE treated with CPAP.

- The type of acidosis on admission - respiratory, metabolic or mixed - does not impact clinical outcomes of ACPE patients treated with CPAP.

\section{Additional material}

Additional file 1: The acidotic population. A Word table presenting demographics, comorbidities, severity of the disease, clinical and laboratory findings on admission and before CPAP treatment of the acidotic population, according to the type of acidemia on admission

\section{Abbreviations}

ACPE: acute cardiogenic pulmonary edema; CPAP: continuous positive airways pressure; ETI: endotracheal intubation; $\mathrm{HCO}_{3}^{-}$: bicarbonates; NIV: noninvasive ventilation; $\mathrm{PaCO}_{2}$ : partial pressure of carbon dioxide in arterial blood; $\mathrm{PaO}_{2} / \mathrm{FiO}_{2}$ : partial pressure of oxygen in arterial blood/inspired oxygen fraction; PEEP: positive end-expiratory pressure.

\section{Author details}

'Dipartimento toraco-polmonare e cardio-circolatorio, University of Milan, IRCCS Fondazione Cà Granda Ospedale Maggiore Policlinico, via F. Sforza 35, 20122 Milan, Italy. ²Emergency Medicine Department, IRCCS Fondazione Cà Granda Ospedale Maggiore Policlinico, via F. Sforza 35, 20122 Milan, Italy.

${ }^{3}$ School of Specialization in Hospital Pharmacy, University of Milan, Via Colombo 71, 20133 Milan, Italy.

\section{Authors' contributions}

SA contributed to the conception and design of the study, as well as the acquisition, analysis and interpretation of data; he was involved in drafting the manuscript and revising it critically for important intellectual content. RC and $A M B$ contributed to the conception and design of the study, the analysis and interpretation of data; they were involved in revising the manuscript. $A A B$ contributed to the conception and design, analysis and interpretation of data; he was involved in revising the manuscript. FP, TM and VDR contributed to the acquisition, analysis and interpretation of the data; they were involved in revising the manuscript critically. VM revised the manuscript. All authors read and approved the final manuscript.

\section{Competing interests}

The authors declare that they have no competing interests.

Received: 18 June 2010 Revised: 5 October 2010

Accepted: 1 November 2010 Published: 1 November 2010

\section{References}

1. Nieminen MS, Böhm M, Cowie MR, Drexler H, Filippatos GS, Jondeau G, Hasin Y, Lopez-Sendon J, Mebazaa A, Metra M, Rhodes A, Swedberg K, Priori SG, Garcia MA, Blanc JJ, Budaj A, Cowie MR, Dean V, Deckers J, Burgos EF, Lekakis J, Lindahl B, Mazzotta G, Morais J, Oto A, Smiseth OA Garcia MA, Dickstein K, Albuquerque A, Conthe $P$, et al: Executive summary of the guidelines on the diagnosis and treatment of acute heart failure: 
the Task Force on Acute Heart Failure of the European Society of Cardiology. Eur Heart J 2005, 26:384-416.

2. Holt AW, Bersten AD, Fuller S, Piper RK, Worthley LI, Vedig AE: Intensive care costing methodology: cost benefit analysis of mask continuous positive airway pressure for severe cardiogenic pulmonary oedema. Anaesth Intensive Care 1994, 22:170-174.

3. Plaisance P, Pirracchio R, Berton C, Vicaut E, Payen D: A randomized study of out-of-hospital continuous positive airway pressure for acute cardiogenic pulmonary oedema: physiological and clinical effects. Eur Heart J 2007, 28:2895-2901.

4. Peter JV, Moran JL, Phillips-Hughes J, Graham P, Bersten AD: Effect of noninvasive positive pressure ventilation (NIPPV) on mortality in patients with acute cardiogenic pulmonary oedema: a meta-analysis. Lancet 2006, 367:1155-1163.

5. Cosentini R, Aliberti S, Bignamini A, Piffer F, Brambilla AM: Mortality in acute cardiogenic pulmonary edema treated with continuous positive airway pressure. Intensive Care Med 2009, 35:299-305.

6. Plant PK, Owen JL, Elliott MW: Non-invasive ventilation in acute exacerbations of chronic obstructive pulmonary disease: long term survival and predictors of in-hospital outcome. Thorax 2001, 56:708-712.

7. Meduri GU, Turner RE, Abou-Shala N, Wunderink R, Tolley E: Noninvasive positive pressure ventilation via face mask. First-line intervention in patients with acute hypercapnic and hypoxemic respiratory failure. Chest 1996, 109:179-193.

8. Confalonieri M, Garuti G, Cattaruzza MS, Osborn JF, Antonelli M, Conti G, Kodric M, Resta O, Marchese S, Gregoretti C, Rossi A, Italian noninvasive positive pressure ventilation (NPPV) study group: A chart of failure risk for noninvasive ventilation in patients with COPD exacerbation. Eur Respir $J$ 2005, 25:348-355.

9. Moretti M, Cilione C, Tampieri A, Fracchia C, Marchioni A, Nava S: Incidence and causes of non-invasive mechanical ventilation failure after initial success. Thorax 2000, 55:819-825.

10. Gray A, Goodacre S, Newby DE, Masson M, Sampson F, Nicholl J, 3CPO Trialists: Noninvasive ventilation in acute cardiogenic pulmonary edema. N Engl J Med 2008, 359:142-151.

11. Antonelli M, Conti G, Moro ML, Esquinas A, Gonzalez-Diaz G, Confalonieri M, Pelaia P, Principi T, Gregoretti C, Beltrame F, Pennisi MA, Arcangeli A, Proietti R, Passariello M, Meduri GU: Predictors of failure of noninvasive positive pressure ventilation in patients with acute hypoxemic respiratory failure: a multi-center study. Intensive Care Med 2001, 27:1718-1728

12. Bellone A, Vettorello M, Monari A, Cortellaro F, Coen D: Noninvasive pressure support ventilation vs. continuous positive airway pressure in acute hypercapnic pulmonary edema. Intensive Care Med 2005, 31:807-811.

13. Kelly BJ, Matthay MA: Prevalence and severity of neurologic dysfunction in critically ill patients. Influence on need for continued mechanical ventilation. Chest 1993, 104:1818-1824.

14. Le Gall JR, Lemeshow S, Saulnier F: A new Simplified Acute Physiology Score (SAPS II) based on a European/North American multicenter study. JAMA 1993, 270:2957-2963.

\section{doi:10.1186/cc9315}

Cite this article as: Aliberti et al: Acidemia does not affect outcomes of patients with acute cardiogenic pulmonary edema treated with continuous positive airway pressure. Critical Care 2010 14:R196.

\section{Submit your next manuscript to BioMed Central and take full advantage of:}

- Convenient online submission

- Thorough peer review

- No space constraints or color figure charges

- Immediate publication on acceptance

- Inclusion in PubMed, CAS, Scopus and Google Scholar

- Research which is freely available for redistribution

Submit your manuscript at www.biomedcentral.com/submit 